\title{
Treatment of Hepatocellular Carcinoma: A Systematic Review
}

\author{
Shibo Lin Katrin Hoffmann Peter Schemmer \\ Department of General and Transplant Surgery, Ruprecht-Karls-University, Heidelberg, Germany
}

\author{
Key Words \\ Chemotherapy · Hepatocellular carcinoma - Liver resection · Liver transplantation · \\ Intervention therapy
}

\begin{abstract}
Hepatocellular carcinoma (HCC) is one of the most common malignancies, with an increasing incidence. With advances in surgical techniques and instrumentation and the development of molecular-target drugs, a number of potentially curative treatments have become available. Management of HCC patients depends on the stage of their tumor. Liver resection remains the first choice for very early-stage HCC, but it is being challenged by local ablative therapy. For early-stage HCC that meet the Milan criteria, liver transplantation still offers a better outcome; however, local ablative therapy can be a substitute when transplantation is not feasible. Local ablation is also used as a bridging therapy toward liver transplantation. HCC recurrence is the main obstacle to successful treatment, and there is currently no effective means of preventing or treating HCC recurrence. Transarterial therapy is considered suitable for intermediate-stage HCC, while sorafenib is recommended for advanced-stage HCC. This stage-based approach to therapy not only provides acceptable outcomes but also improves the quality of life of HCC patients. Because of the complexity of HCC, therapeutic approaches must be adapted according to the characteristics of each individual patient. This review discusses the current standards and trends in the treatment of HCC.
\end{abstract}




\section{Introduction}

Hepatocellular carcinoma (HCC) is the fifth most common form of cancer and the third leading cause of cancer-related death worldwide [1]. The number of cases diagnosed with HCC is expected to increase in Western countries [2]. Therapeutic approaches for the treatment of HCC can be classified into three categories: potentially curative, palliative, and symptomatic. Potentially curative treatments, including liver resection, transplantation, and local ablation, are associated with promising 5-year survival rates of up to 75\% [3]. However, because of a shortage of donor livers, advanced tumor stage, or liver dysfunction, less than $20 \%$ HCC patients are eligible for such treatments $[4,5]$. The majority of HCC patients are subjected to palliative or symptomatic treatment. The 3-year survival rate for palliative treatment is $10-40 \%$, and the duration of survival for patients who receive symptomatic treatment is $<3$ months [6]. The choice of therapy is mainly based on by the stage of HCC, severity of the underlying liver disease, availability of treatment resources, and clinical expertise [7]. Selection criteria for these treatments have been recommended by Bruix and Sherman et al. [8, 9].

Stage evaluation is essential to assess the resectability of the tumor mass, choose an appropriate therapy, and predict the prognosis of HCC patients. Numerous staging evaluation systems have been proposed and applied in clinical practice, including the Cancer of the Liver Italian Program (CLIP) score, Barcelona Clinic Liver Cancer (BCLC) staging, Groupe d'Etude et de Traitement du Carcinome Hépatocellulaire (GETCH) classification, Chinese University Prognostic Index (CUPI) grade, Japan Integrated Staging (JIS) score, modified JIS (mJIS) score, Okuda staging, and the Tokyo score. Comparisons of the different staging systems are mainly based on retrospective analyses. We collected data from the past five years, and these are summarized in table 1 . Although these data do not suggest any consensus, the BCLC staging system has been proposed as a standard for the assessment of prognosis in Europe and the United States [7, 9]. The exclusion of risk factors in the current staging systems may potentially decrease prognostic accuracy.

\section{Therapeutic Strategies Based on HCC Stage}

\section{Very early stage HCC}

Very early stage HCC is defined as asymptomatic solitary HCC with a diameter of $<2 \mathrm{~cm}$. Surgical resection is recommended by the European Association for the Study of the LiverAmerican Association for the Study of Liver Diseases (EASL-AASLD) for patients who present with very early-stage HCC and Child-Pugh A liver function [8]. The overall 5-year survival and recurrence rates after liver resection of very early-stage HCC are reportedly 70 and $68 \%$, respectively [10]. The presence of satellite nodules and platelet counts $<150,000 / \mu \mathrm{l}$ are independently associated with survival, whereas the presence of satellite nodules and cirrhosis and the use of nonanatomic resection are independently associated with tumor recurrence [10]. Percutaneous ablation can achieve an acceptable outcome for very earlystage HCC: a 5-year disease-free survival rate of $62 \%$ and a 5-year overall survival rate of $78 \%$ [11]. Furthermore, it has been suggested that radiofrequency ablation (RFA) leads to better overall survival in patients with operable HCC than in those with inoperable HCC. Some groups have suggested that RFA should be considered as first-line therapy even when resection is possible because it is associated with fewer side effects [12]. The question of whether surgical resection is superior to RFA remains controversial. Wang et al. suggested that although surgical resection was equivalent to RFA in terms of overall survival, it yielded better disease-free survival [13]. Markov model analysis also indicated that surgical resection was preferable to RFA in terms of overall survival [14]. However, Peng et al. reported 


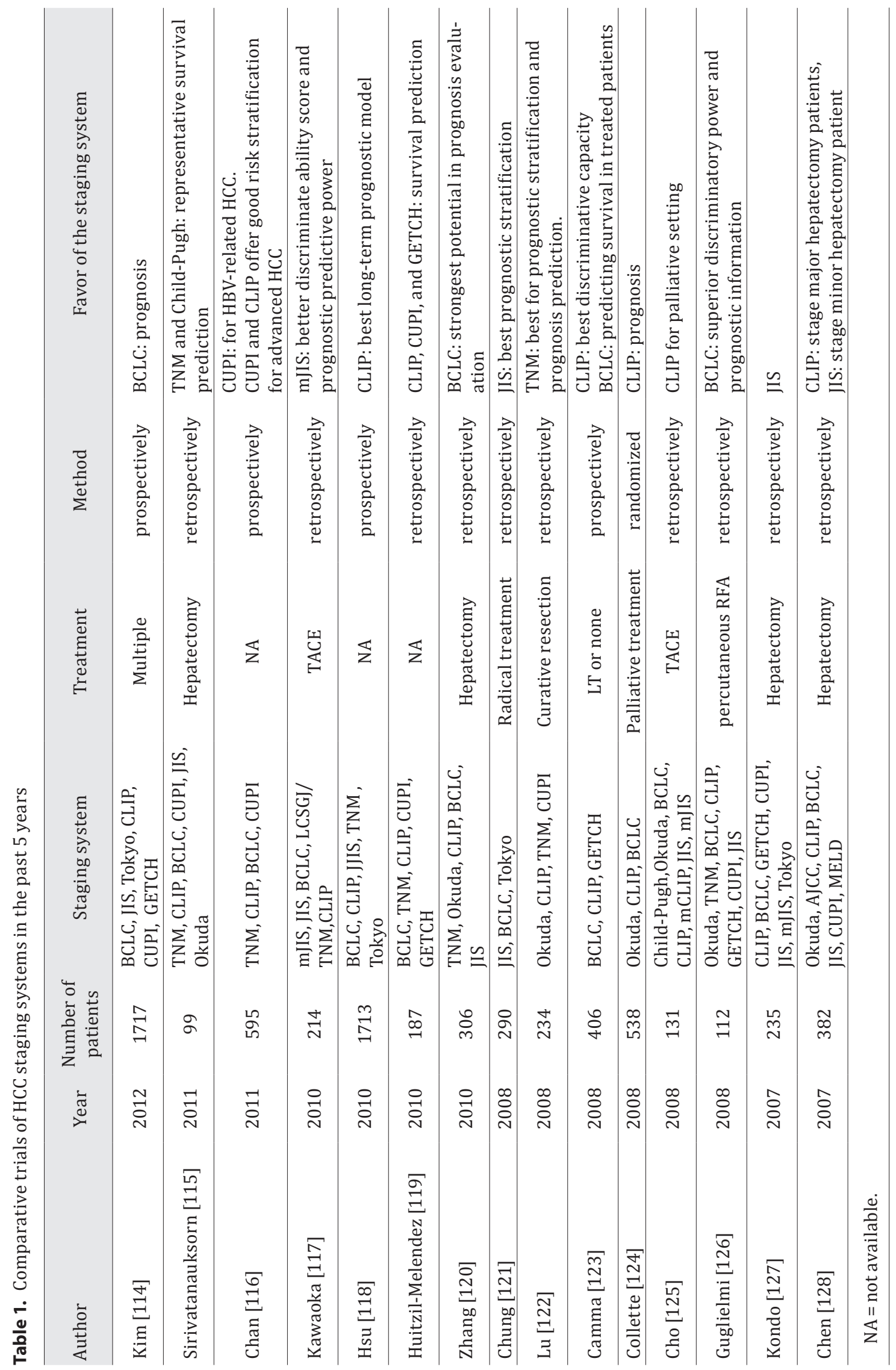




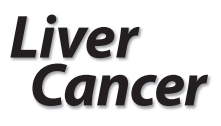

\begin{tabular}{l|l}
\hline \multicolumn{2}{l}{ Liver Cancer 2012;1:144-158 } \\
\hline DOI: 10.1159/000343828 & $\begin{array}{l}\text { ( ) 2012 S. Karger AG, Basel } \\
\text { www.karger.com/lic }\end{array}$ \\
Published online: November 26, 2012 &
\end{tabular}

Table 2. Summary of trials analyzing liver resection vs. local ablative therapies in the past 5 years

\begin{tabular}{|c|c|c|c|c|c|c|c|c|c|c|}
\hline Author & Year & Methodology & $\begin{array}{l}\text { Treat- } \\
\text { ments }\end{array}$ & $\begin{array}{l}\text { Patients } \\
\text { number }\end{array}$ & $\begin{array}{l}\text { Tumor } \\
\text { number }\end{array}$ & $\mathrm{D}(\mathrm{cm})$ & OSR & ORS & RFSR & DFSR \\
\hline Feng [129] & 2012 & RCT & $\begin{array}{c}\text { SR } \\
\text { RFA }\end{array}$ & $\begin{array}{l}84 \\
84\end{array}$ & $\leq 2$ & $\leq 4$ & $x$ & $x$ & $x$ & NA \\
\hline $\begin{array}{l}\text { Ruzzenente } \\
{[130]}\end{array}$ & 2012 & $\begin{array}{c}\text { Retrospective, } \\
\text { Case matched }\end{array}$ & $\begin{array}{l}\text { SR } \\
\text { LAT }\end{array}$ & $\begin{array}{l}88 \\
88\end{array}$ & $\leq 3$ & $\leq 5$ & $x$ & NA & NA & $x$ \\
\hline Wang [13] & 2012 & Retrospective & $\begin{array}{c}\text { SR } \\
\text { RFA }\end{array}$ & $\begin{array}{l}208 \\
254\end{array}$ & $\leq 3$ & $\leq 5$ & $\mathrm{SR}>\mathrm{RFA}$ & $\mathrm{SR}<\mathrm{RFA}$ & NA & $\mathrm{SR}>\mathrm{RFA}$ \\
\hline Huang [131] & 2011 & Retrospective & $\begin{array}{c}\text { SR } \\
\text { RFA }\end{array}$ & $\begin{array}{l}311 \\
212\end{array}$ & 1 & $\leq 3$ & $\mathrm{SR}>\mathrm{RFA}$ & $x$ & $x$ & $\mathrm{SR}>\mathrm{RFA}$ \\
\hline Huang [131] & 2011 & Retrospective & $\begin{array}{c}\text { SR } \\
\text { RFA }\end{array}$ & $\begin{array}{l}337 \\
201\end{array}$ & $\leq 3$ & $3<\mathrm{D}<5$ & $\mathrm{SR}>\mathrm{RFA}$ & $x$ & $\mathrm{SR}>\mathrm{RFA}$ & $\mathrm{SR}>\mathrm{RFA}$ \\
\hline Hung [132] & 2011 & $\begin{array}{c}\text { Retrospective, } \\
\text { Case matched }\end{array}$ & $\begin{array}{c}\text { SR } \\
\text { RFA }\end{array}$ & $\begin{array}{l}229 \\
190\end{array}$ & $\leq 3$ & $\leq 5$ & $x$ & $\mathrm{SR}<\mathrm{RFA}$ & NA & NA \\
\hline $\begin{array}{l}\text { Nishikawa } \\
{[133]}\end{array}$ & 2011 & Retrospective & $\begin{array}{c}\text { SR } \\
\text { RFA }\end{array}$ & $\begin{array}{c}69 \\
162\end{array}$ & 1 & $\leq 3$ & $x$ & NA & $x$ & NA \\
\hline Huang [134] & 2010 & RCT & $\begin{array}{c}\text { SR } \\
\text { RFA }\end{array}$ & $\begin{array}{l}115 \\
115\end{array}$ & $\leq 3$ & $\leq 5$ & $\mathrm{SR}>\mathrm{RFA}$ & $\mathrm{SR}<\mathrm{RFA}$ & $\mathrm{SR}>\mathrm{RFA}$ & NA \\
\hline
\end{tabular}

$\mathrm{SR}=$ surgical resection; PTA=percutaneous thermal ablation; D=Diameter of tumor mass; OSR=overall survival rates; ORS = overall recurrence rates; RFSR = recurrence-free survival rates; DFSR = disease-free survival rates; $x=$ no significance.

that RFA was associated with better overall survival compared with surgical resection [15]. Therefore, further research is warranted before local ablation can be recommended as firstline therapy for very early-stage HCC or as a substitute for surgical resection.

\section{Early-stage HCC}

Early-stage HCC is defined according to the Milan criteria as follows: a single tumor nodule $\leq 5 \mathrm{~cm}$ in diameter or $\leq 3$ nodules $\leq 3 \mathrm{~cm}$ in diameter [16]. Approximately $25 \%$ of all HCC patients are diagnosed with early-stage HCC [17]. According to the EASL-AASLD guidelines, early-stage HCC is an indication for liver transplantation or RFA [8]. Liver transplantation is the optimal approach, but local ablation can be a substitute when liver transplantation is not feasible. Liver resection should be considered when patients present with a solitary tumor and no portal hypertension [7]. The 4- and 5-year survival rates of patients who meet the Milan criteria and subsequently undergo liver transplantation are 85 and $70 \%$, respectively $[16,18]$. Farinati et al. reported that for patients with early-stage HCC, liver transplantation offers the best chances of survival (106 months) compared with surgical resection (52 months), RFA (62 months), percutaneous ethanol injection (PEI, 44 months), and transarterial chemoembolization (TACE, 34 months) [17]. Despite the excellent efficacy of liver transplantation in early-stage HCC treatment, a shortage of donor livers or tumor progression during the waiting period inevitably leads to patients dropping out from the waiting list. The monthly drop-out rate is approximately $4 \%[18,19]$. Local ablative therapies, primarily RFA, have therefore been investigated as alternative treatments for early-stage HCC that meet the Milan criteria. Although a recent meta-analysis indicated that surgical resection is superior to RFA because it results in longer overall survival, longer recurrence-free survival, and a low rate of local recurrence, the analysis was mainly based on nonrandomized controlled trials and did not include the latest 3-year survival data [20]. The conclusion should therefore be interpreted with caution. To address the efficacy of local ablative therapy in comparison with 
Table 3. Summary of transarterial therapies for HCC

\begin{tabular}{|c|c|c|c|c|c|c|c|c|}
\hline \multirow{2}{*}{ Author } & \multirow{2}{*}{ Year } & \multirow{2}{*}{ Treatment } & \multirow{2}{*}{$\begin{array}{c}\text { Number of } \\
\text { patients }\end{array}$} & \multicolumn{4}{|c|}{ Overall survival (OS) (\%) } & \multirow{2}{*}{$\begin{array}{c}\text { OS (Months) } \\
\text { Median }\end{array}$} \\
\hline & & & & 1 year & 2 years & 3 years & 4 years & \\
\hline \multirow{2}{*}{ Doffoël [95] } & \multirow{2}{*}{2008} & TACE+tamoxifen & 62 & 51 & 25 & NA & NA & 13.8 \\
\hline & & tamoxifen & 61 & 46 & 22 & NA & NA & 11.0 \\
\hline \multirow{2}{*}{ Lo [94] } & \multirow{2}{*}{2002} & TACE & 40 & $57 *$ & $31^{*}$ & $26^{*}$ & NA & NA \\
\hline & & symptomatic & 40 & 32 & 11 & 3 & NA & NA \\
\hline \multirow{3}{*}{ Llovet [93] } & \multirow{3}{*}{2002} & TACE & 38 & $82 *$ & $63^{*}$ & 29 & NA & $28.7^{*}$ \\
\hline & & TAE & 34 & 75 & 50 & 29 & NA & 25.3 \\
\hline & & symptomatic & 35 & 63 & 27 & 17 & NA & 17.9 \\
\hline \multirow{2}{*}{ Bruix [97] } & \multirow{2}{*}{1998} & TAE & 40 & NA & 49 & NA & 13 & NA \\
\hline & & symptomatic & 40 & NA & 50 & NA & 27 & NA \\
\hline \multirow{2}{*}{ GETCH [135] } & \multirow{2}{*}{1995} & TACE & 50 & 62 & 37.8 & NA & NA & NA \\
\hline & & Conservative & 46 & 43.5 & 24.3 & NA & NA & NA \\
\hline
\end{tabular}

that of surgery, we have summarized data from recent clinical trials in table 2. As shown in the table, the superiority of surgical resection remains controversial. More randomized controlled trials are warranted to elucidate whether local ablative therapy and surgical resection have equivalent efficacy for the treatment of early-stage HCC.

\section{Intermediate-stage HCC}

HCC patients with Child-Pugh A and B liver function who present with a large or multifocal tumor mass without cancer-related symptoms, macrovascular invasion, or extrahepatic spread are diagnosed with intermediate-stage HCC. Transarterial therapy, especially TACE, is recommended for this stage of HCC by the EASL-AASLD guidelines. Randomized controlled trials of treatments for intermediate-stage HCC are summarized in table 3. Of the five trials reported, only two favored TACE over symptomatic treatment in terms of overall survival. Approximately $20-30 \%$ HCC patients are diagnosed with intermediate-stage HCC, and more trials are required to elucidate the efficacy of transarterial therapy for these patients [21, 22]. A surgical approach has also been adopted in this patient population. Vitale et al. reported that the 3-year survival rate among patients with intermediate-stage HCC who underwent surgery was $56 \%$ compared to $13 \%$ among those who did not [22]. It has been suggested that liver transplantation should be considered critical for intermediate-stage HCC [23]. However, surgical resection for intermediate-stage HCC is associated with poor long-term survival rates; the 3-, 5-, and 10-year survival rates after surgical resection are reportedly 35.1, 18.2, and $3.5 \%$, respectively [24].

\section{Advanced-stage HCC and terminal-stage HCC}

HCC with cancer-related symptoms, vascular invasion, or extrahepatic spread is considered to be in the advanced stage. The therapeutic recommendation for this stage is oral sorafenib treatment. Despite improvements in survival after sorafenib administration, the prognosis for patients with this stage of HCC is still poor, with a median overall survival rate of 6.5-10.7 months [25]. Terminal-stage HCC includes severe deterioration of physical capacity and symptoms related to liver failure, vascular invasion, or extrahepatic spread. At this stage, only symptomatic treatments are available, and the median survival is $<3$ months [9]. 


\section{Therapeutic Approaches for HCC}

\section{Liver resection}

Surgical resection is considered a potentially curative treatment and offers an acceptable outcome for carefully selected HCC patients [26, 27]. Refinements of surgical techniques and staging systems have led to 5-year survival rates of approximately $50-70 \%$ after surgical resection [28-31]. The application of advanced surgical techniques and instrumentation decreases blood loss, increases outcomes such as survival and quality of life, and decreases the need for the Pringle maneuver compared with that for portal triad clamping [32-35]. As mentioned above, the best candidates for surgical resection are patients with very early- or early-stage HCC, although resection in patients with more advanced stages of HCC has been reported with acceptable outcomes [24, 36, 37]. Tumor size, tumor nodules, liver function, and portal pressure have been identified as prognostic predictors after liver resection [29, $38,39]$. Surgical resection is likely to remain the primary approach for patients who present with very early- and early-stage HCC, given its apparent superiority to liver transplantation and local ablative therapy. Although liver transplantation offers a better outcome, the shortage of donor livers remains indisputable. Surgical resection also enables complete pathological analysis of a cancerous sample, which cannot be achieved by local ablative therapy. Complete resection (R0) is indispensible for decreasing recurrence, but an adequately sized liver remnant is required to avoid postoperative liver failure [40]. Major liver resection is feasible, and up to $70 \%$ of a noncirrhotic liver can be resected considering that liver regeneration, which is compensatory growth that restores liver mass and function after liver resection, occurs $[41,42]$. The minimal critical remnant liver volume for resection is approximately $25 \%$ $(15-40 \%)$ for noncirrhotic and 50\% (25-90\%) for cirrhotic livers [43]. When the estimated volume of the future liver remnant does not meet these criteria, preoperative portal vein embolization (PVE) is recommended [44]. Preoperative PVE reportedly decreases the rate of postoperative complications in cirrhotic patients but not in patients with normal livers [45]. Recurrence after liver resection remains the major obstacle to achieving ideal survival, and the 5-year recurrence rates are approximately $70 \%[10,46]$. The prognosis for HCC patients after liver resection is mainly influenced by the recurrence of HCC, either a real recurrence or a de-novo tumor growth in a cirrhotic liver $[47,48]$. The risk factors contributing to recurrence after curative resection have yet to be elucidated. The intrahepatic spread of resected primary HCC has been conceptually attributed to early recurrence (within 2 years after resection), while precancerous lesions in the remnant liver after resection may be involved in later recurrence [49]. Re-resection, RFA, and salvage liver transplantation are potential therapeutic approaches to intrahepatic recurrence. Chan et al. reported 1-, 3-, and 5-year overall survival rates of $89.7,56.5$, and $35.2 \%$ after re-resection and 83.7, 43.1, and $29.1 \%$ after RFA in patients with recurrent HCC [50]. If the recurrent HCC meets the Milan criteria, salvage liver transplantation can also be considered [51]. For carefully selected patients, salvage liver transplantation can achieve a 5-year survival rate of approximately $70 \%$, which is similar to that achieved with primary liver transplantation [52].

Laparoscopic liver resection is a minimally invasive surgical approach that is gaining importance in the treatment of HCC. Till date, most of segmental liver resections can be performed laparoscopically, but major laparoscopic hepatectomy (LH) has also been reported $[53,54]$. However, selection criteria must be adapted to the clinical expertise of the surgeon to avoid any unnecessary conversion to open hepatectomy $(\mathrm{OH})$ or serious complications. Although LH is a more sophisticated surgical procedure compared with $\mathrm{OH}$, the use of laparoscopic ultrasound and a hand port, cavitron ultrasonic aspirator (CUSA ${ }^{\mathrm{TM}}$ ), vessel sealing system (Ligasure ${ }^{\mathrm{TM}}$ ), and ultrascision scissors (Autosonix ${ }^{\mathrm{TM}}$ ) decreases intraoperative bleeding, facilitates safe parenchyma transection, and increases the scope for vessel division. 
Hemorrhage and insufficient tumor excision are the two main reasons for conversion to $\mathrm{OH}$. Potential complications are similar to those for open resection and include bile leakage, hemorrhage, hepatic failure, and infections [55]. Recent evidence has indicated that there is no difference between $\mathrm{LH}$ and $\mathrm{OH}$ in terms of margin status, recurrence, and survival [56]. Furthermore, LH decreases blood loss, frequency of transfusion, frequency of use of the Pringle maneuver, postoperative morbidity, recovery time, length of hospital stay, and the incidence of incisional hernia when compared with $\mathrm{OH}$ [57]. These advantages were confirmed in a recent meta-analysis [58]. However, all of this evidence is based on retrospective or casematched retrospective analyses, and no randomized controlled trials have been reported. The proposed advantages need to be validated using such trials to confirm the long-term effects of laparoscopic liver resection on survival and tumor metastasis.

\section{Liver transplantation}

Liver transplantation offers a better oncological outcome than surgical resection because it not only removes all precancerous and cancerous lesions within the liver but also cures the coexisting liver disease. Early outcomes of liver transplantation for HCC were poor, with 5 -year survival rates of 15-40\% [59-61]. However, after the establishment of the Milan criteria, the 5-year survival rate increased to $70-80 \%[62,63]$. Yet, there is a tendency to expand the Milan criteria for liver transplantation, and 5-year survival rates of $45-55 \%$ are considered acceptable even though such an extension of the Milan criteria increases the incidence of HCC recurrence [63-65]. The outcomes of liver transplantation for HCC patients who were treated at our center and exceeded the Milan criteria were comparable with those of patients in a previous study [66]. The scarcity of donor livers remains the main obstacle for HCC patients and increases the waiting time for transplantation. HCC progression during the waiting period leads to patients dropping out from the waiting list; the monthly drop-out rate is reportedly $4 \%[18,19]$. One potential solution to this problem is increasing the donor pool by live donation, which is mostly practiced in Asia, using bridging therapy such as local ablative treatments for HCC patients on the waiting list, and applying prioritization policies [67].

The first living donor liver transplantation (LDLT) was reported in 1989 by Raia [68], and successful LDLT from an adult to a child was achieved one year later [69]. Successful adultto-adult LDLT was reported in 1994 [70]. LDLT is now performed worldwide and has become an alternative to deceased donor liver transplantation (DDLT) [71]. The surgical protocols and evaluation criteria for donors as well as recipients are now well established [72, 73]. Recent reports suggest that outcomes for LDLT are similar to those for DDLT in terms of overall survival and recurrence rates, but the waiting time is lower with LDLT than with DDLT [74]. Both left- and right-lobe LDLT are performed, and the more preferable option remains controversial. Taketomi et al. reported that the long-term outcome of HCC patients who underwent left-lobe LDLT was similar to that of patients who underwent right-lobe LDLT; however, those with left-lobe LDLT achieved lower peak postoperative total bilirubin levels and had a shorter hospital stay after transplantation [75]. In contrast, Saidi et al. reported that recipients of leftlobe LDLT had a greater mean duration of stay (24.9 days vs. 18.2 days), higher re-transplantation rates (20.3\% vs. $10.9 \%)$, lower allograft survival, and inferior survival compared with recipients of DDLT [76]. LDLT should be carefully considered because donor morbidity and mortality still exist, and problems such as matching the graft size with the recipient area and postoperative complications cannot be avoided [77].

Progression of HCC during the waiting period for liver transplantation is inevitable and can lead to patients dropping out from the waiting list. The current strategy is to use RFA or TACE as bridging therapy to decrease tumor progression when the estimated waiting time for transplantation is longer than six months [67]. Percutaneous treatments are more costeffective than surgical resection [78]. The use of RFA as a bridge to liver transplantation re- 
Table 4. Meta-analysis of local ablative therapy and liver resection

\begin{tabular}{ll}
\hline Methods & \multicolumn{1}{c}{ Conclusions } \\
\hline $\begin{array}{l}\text { RFA vs. LR } \\
{[20,136]}\end{array}$ & $\begin{array}{l}\text { 1: LR exhibited higher overall and recurrence-free survival rates of 1, 3, and 5 } \\
\text { years compared with RFA. } \\
\text { 2: the rate of local recurrence was lower with hepatectomy than with RFA. } \\
\text { 3: postoperative morbidity was higher with hepatectomy. }\end{array}$ \\
\hline $\begin{array}{l}\text { 1: RFA was superior to PEI in terms of survival, complete necrosis of tumor, and } \\
\text { local recurrence. }\end{array}$ \\
$\begin{array}{ll}\text { 2: For tumors }<2 \text { cm, RFA was not significantly better than PEI. } \\
\text { 3: The overall rate of adverse events was higher with RFA than with PEI. }\end{array}$ \\
$\begin{array}{ll}\text { PAI vs. PEI } & \text { PAI did not differ significantly from PEI in terms of overall survival, recurrence- } \\
\text { f137, 139] } & \text { RFA resulted in lower local recurrence } \\
\text { RFA vs. PAI } & \end{array}$ \\
{$[137]$}
\end{tabular}

portedly enables HCC patients to remain on the waiting list for longer without influencing post-transplantation outcomes [79]. Furthermore, a poor response to TACE before transplantation is an indicator of post-transplantation recurrence [80]. Downstaging of HCC to within the Milan criteria may be another benefit of these treatments, with acceptable survival rates [81-84].

The Model for End-Stage Liver Disease (MELD) allocation policy is a widely accepted allocation system that decreases the waiting time and drop-out rates [85, 86]. A recent analysis indicated that MELD provided reasonable patient and graft survival but increased the financial burden and post-transplantation morbidity [87]. A new allocation system, the BAR system, has been proposed. This appears to predict survival in a better manner [88]. This system includes the six strongest predictors of post-transplantation survival: recipient MELD score, cold ischemia time, recipient age, donor age, previous orthotopic liver transplant, and life support dependence prior to transplantation. However, its efficacy needs to be clinically validated.

\section{Local ablative therapy}

Local ablative therapy can be classified into two categories: chemical ablation and thermal ablation. The substances involved in chemical ablation are ethanol and acetic acid, whereas thermal ablation uses radiofrequency, microwaves, cryoablation, lasers, and ultrasound. Local ablation is recommended for patients with small HCCs confined to the liver, which are unresectable because of compromised liver function [89]. Local ablative therapy, especially RFA, has already been proven to be effective, particularly for very early- and early-stage HCC; however, its superiority to surgical resection remains controversial. We have summarized evidence-based meta-analysis findings of such comparisons in table 4. RFA appears to be superior to all other local ablative therapies. For unresectable HCC, local ablative therapy has also been shown to be efficacious when combined with TACE. Lubienski et al. reported that the 3-year survival rate was longer with a combination of TACE and PEI (22\%) than with TACE alone (4\%) in patients with large and unresectable HCC [90].

\section{Transarterial therapy}

Differences in blood supply to the liver and HCC form the theoretical basis of transarterial therapy. The liver receives $25 \%$ of its blood supply from the hepatic artery and $75 \%$ 
from the portal vein, whereas HCC receives $90 \%$ of its blood supply from the hepatic artery and only $10 \%$ from the portal vein [91]. This difference provides the rationale for transarterial obstruction with or without regional chemotherapy to block the blood supply to HCC and induce tumor necrosis without significantly influencing the blood supply to the liver [92]. Transarterial therapies includes TACE, transarterial embolization (TAE), transarterial bland embolization, transarterial chemotherapy, and transarterial radioembolization, but the optimal procedure remains controversial [92]. The efficacy of transarterial therapy is also controversial [93-97]. The latest meta-analysis, which included six trials assessing TACE versus a control and three trials assessing TAE versus a control, concluded that TACE or TAE did not significantly increase survival in patients with unresectable HCC compared with controls, and there was no firm evidence to support or refute the use of TACE or TAE [96]. Of note, transarterial therapy has increased the risk of liver failure in some reports [92, 94]. The hepatic artery supplies $50 \%$ of the oxygen consumed by the liver [98]; therefore, blocking the hepatic artery decreases the oxygen supply, which may be responsible for transarterial therapy-related liver failure.

\section{Sorafenib}

The emergence of sorafenib highlights the treatment of advanced HCC. Sorafenib is a tyrosine kinase inhibitor of Raf serine/threonine kinases, vascular endothelial growth factor receptor (VEGFR-1, VEGFR-2, VEGFR-3), and platelet-derived growth factor receptor-h (PDGFRh) tyrosine kinases [99]. A prospective randomized controlled trial concluded that sorafenib significantly improved the median overall survival and the median time to radiological progression in patients with advanced HCC [25]. These results were further confirmed by Cheng et al. in Asian patients [100]. Sorafenib was approved by the FDA for the treatment of unresectable HCC and recommended as the first-line therapy for HCC patients who cannot benefit from therapies that are potentially more effective, such as TACE or local ablative therapy [8]. A subanalysis was conducted to assess the multiple risk factors involved in HCC oncogenesis, and this revealed that sorafenib can also be beneficial for patients with alcohol-related HCC or hepatitis B or hepatitis C infection [101].

The prognosis for patients with advanced HCC is poor. Although sorafenib has a positive effect on the survival of patients with advanced HCC, the response to sorafenib remains low and the median overall survival is only extended by 2.8 months [25]. To optimize the beneficial effects of sorafenib, combination therapies comprising sorafenib and conventional chemotherapy or TACE have been investigated. A randomized trial comparing the combination of sorafenib and doxorubicin with doxorubicin alone found a median time to progression of 6.4 months vs. 2.8 months, median overall survival of 13.7 months vs. 6.5 months, and progression-free survival of 6.0 months vs. 2.7 months, respectively [101]. These findings confirm the efficacy of sorafenib for advanced HCC but do not prove that the combination of sorafenib and doxorubicin is superior to sorafenib alone. Moreover, doxorubicin-based chemotherapy for HCC has already been ruled out by another randomized controlled trial [102]. Further trials comparing the combination of sorafenib and chemotherapy with sorafenib alone are warranted. Interestingly, sorafenib modulates the gene expression of multi-drug resistance mediating, ATP-binding cassette proteins in experimental HCC [103].

It has been reported that HCC patients who respond to TACE do not benefit from sorafenib treatment [104]. However, a randomized trial that included 80 patients with chronic HCV infection found that conventional TACE followed by sorafenib resulted in a significantly longer time to progression [105]. Based on these controversial results, further trials with a larger number of patients are required to validate the effects of sequential sorafenib treatment after TACE. Synchronous therapy with sorafenib and TACE has also been retrospectively analyzed, and researchers have found that the median overall survival for the combined treatment 
group was 27 months compared with 17 months for the TACE-alone group [106]. A phase III clinical study evaluating sorafenib and TACE versus TACE alone is ongoing [107]. Further trials comparing sorafenib combined with TACE with sorafenib alone are also needed to validate the efficacy of combination therapy.

\section{Chemotherapy}

Chemotherapeutic choices for HCC are limited. Systemic chemotherapy with doxorubicin, gemcitabine, or combined regimens for palliative care reportedly provide only marginal improvements in survival of HCC patients $[102,108,109]$. The high intrinsic and acquired drug resistance of HCC is mainly responsible for the failure of systemic chemotherapy [110]. Doxorubicin is a common anticancer agent in clinical practice. However, intravenous doxorubicin treatments only have limited efficacy in HCC patients [111]. A prospective randomized controlled trial revealed that doxorubicin monotherapy only provided a 3-week increase in median survival compared with no chemotherapy. Moreover, doxorubicin treatment resulted in severe complications such as septicemia and cardiotoxicity, which could not be tolerated by the patients [102]. The toxicity of gemcitabine is less severe than that of doxorubicin, but its therapeutic efficacy is similar. A phase II study of gemcitabine in patients with advanced HCC showed that gemcitabine only had marginal anti-tumor effects $[108,112]$. A randomized phase III study was conducted to investigate whether the combination of cisplatin, interferon, doxorubicin, and fluorouracil (PIAF) was more effective in treating HCC compared with doxorubicin alone [109]. A total of 188 HCC patients were included in the trial. The median survival rate of the doxorubicin and PIAF groups was 6.83 months and 8.67 months, respectively, and no significant difference was detected. However, treatment with the PIAF regimen significantly increased the incidence of chemotherapeutic complications such as neutropenia, thrombocytopenia, and hypokalemia. Together, these findings indicate that conventional chemotherapy is ineffective for HCC.

\section{Summary}

HCC is a complex disease associated with multiple risk factors that have direct impacts on the characteristics of HCC patients, the therapy chosen, the disease course, and the prognosis $[2,113]$. Current evidence indicates that potentially curative treatments result in excellent outcomes for very early- and early-stage HCC. However, the therapeutic efficacy of treatments for the vast majority of HCC patients urgently needs to be enhanced.

\section{Acknowledgement}

We thank Katherine Hughes for her editing of the manuscript.

\section{References}

1 Caldwell S, Park SH: The epidemiology of hepatocellular cancer: from the perspectives of public health problem to tumor biology. J Gastroenterol 2009;44(Suppl 19):96-101.

2 Venook AP, Papandreou C, Furuse J, et al: The incidence and epidemiology of hepatocellular carcinoma: a global and regional perspective. Oncologist 2010;15(Suppl 4):5-13.

3 El-Serag HB, Marrero JA, Rudolph L, et al: Diagnosis and treatment of hepatocellular carcinoma. Gastroenterology 2008;134:1752-1763. 
4 Davila JA, Duan Z, McGlynn KA, et al: Utilization and Outcomes of Palliative Therapy for Hepatocellular Carcinoma: A Population-based Study in the United States. J Clin Gastroenterol 2012;46:71-77.

5 Clark HP, Carson WF, Kavanagh PV, et al: Staging and current treatment of hepatocellular carcinoma. Radiographics 2005;25(Suppl 1):S3-S23.

6 Cabrera R, Nelson DR: Review article: the management of hepatocellular carcinoma. Aliment Pharmacol Ther 2010;31:461-476.

7 El-Serag HB: Hepatocellular carcinoma. N Engl J Med 2011;365:1118-1127.

8 Bruix J, Sherman M: Management of hepatocellular carcinoma: an update. Hepatology 2011;53:1020-1022.

9 Bruix J, Sherman M: Management of hepatocellular carcinoma. Hepatology 2005;42:1208-1236.

10 Roayaie S, Obeidat K, Sposito C, et al: Resection of hepatocellular cancer $</=2 \mathrm{~cm}$ : results from two western centers. Hepatology 2012.

11 Kuang M, Xie XY, Huang C, et al: Long-term outcome of percutaneous ablation in very early-stage hepatocellular carcinoma. J Gastrointest Surg 2011;15:2165-2171.

12 Livraghi T, Meloni F, Di Stasi M, et al: Sustained complete response and complications rates after radiofrequency ablation of very early hepatocellular carcinoma in cirrhosis: Is resection still the treatment of choice? Hepatology 2008;47:82-89.

13 Wang JH, Wang CC, Hung CH, et al: Survival comparison between surgical resection and radiofrequency ablation for patients in BCLC very early/early stage hepatocellular carcinoma. J Hepatol 2012;56:412-418.

14 Cho YK, Kim JK, Kim WT, et al: Hepatic resection versus radiofrequency ablation for very early stage hepatocellular carcinoma: a Markov model analysis. Hepatology 2010;51:1284-1290.

15 Peng ZW, Lin XJ, Zhang YJ, et al: Radiofrequency ablation versus hepatic resection for the treatment of hepatocellular carcinomas $2 \mathrm{~cm}$ or smaller: a retrospective comparative study. Radiology 2012;262:10221033.

16 Mazzaferro V, Regalia E, Doci R, et al: Liver transplantation for the treatment of small hepatocellular carcinomas in patients with cirrhosis. N Engl J Med 1996;334:693-699.

17 Farinati F, Sergio A, Baldan A, et al: Early and very early hepatocellular carcinoma: when and how much do staging and choice of treatment really matter? A multi-center study. BMC Cancer 2009;9:33 doi:10.1186/1471-2407-9-33.

18 Sarasin FP, Majno PE, Llovet JM, et al: Living donor liver transplantation for early hepatocellular carcinoma: A life-expectancy and cost-effectiveness perspective. Hepatology 2001;33:1073-1079.

19 Llovet JM, Schwartz M, Mazzaferro V: Resection and liver transplantation for hepatocellular carcinoma. Semin Liver Dis 2005;25:181-200.

20 Li L, Zhang J, Liu X, et al: Clinical outcomes of radiofrequency ablation and surgical resection for small hepatocellular carcinoma: a meta-analysis. J Gastroenterol Hepatol 2012;27:51-58.

21 Kudo M, Han KH, Kokudo N, et al: Liver Cancer Working Group report. Jpn J Clin Oncol 2010;40(Suppl 1):i19-i27.

22 Vitale A, Saracino E, Boccagni P, et al: Validation of the BCLC prognostic system in surgical hepatocellular cancer patients. Transplant Proc 2009;41:1260-1263.

23 Choi J Y: Treatment algorithm for intermediate and advanced stage hepatocellular carcinoma: Korea. Oncology 2011;81(Suppl 1):141-147.

24 Chen XP, Qiu FZ, Wu ZD, et al: Hepatectomy for huge hepatocellular carcinoma in 634 cases. World J Gastroenterol 2006;12:4652-4655.

25 Llovet JM, Ricci S, Mazzaferro V, et al: Sorafenib in advanced hepatocellular carcinoma. N Engl J Med 2008;359:378-390.

26 Ryder SD: Guidelines for the diagnosis and treatment of hepatocellular carcinoma (HCC) in adults. Gut 2003;52(Suppl 3):iii1-iii8.

27 Taura K, Ikai I, Hatano E, et al: Influence of coexisting cirrhosis on outcomes after partial hepatic resection for hepatocellular carcinoma fulfilling the Milan criteria: an analysis of 293 patients. Surgery 2007;142:685-694.

28 Young AL, Adair R, Prasad KR, et al: Hepatocellular carcinoma within a noncirrhotic, nonfibrotic, seronegative liver: surgical approaches and outcomes. J Am Coll Surg 2012;214:174-183.

29 Zhou XD, Tang ZY, Yang BH, et al: Experience of 1000 patients who underwent hepatectomy for small hepatocellular carcinoma. Cancer 2001;91:1479-1486.

30 Poon RT, Fan ST, Lo CM, et al: Long-term survival and pattern of recurrence after resection of small hepatocellular carcinoma in patients with preserved liver function: implications for a strategy of salvage transplantation. Ann Surg 2002;235:373-382.

31 Lee KK, Kim DG, Moon IS, et al: Liver transplantation versus liver resection for the treatment of hepatocellular carcinoma. J Surg Oncol 2010;101:47-53.

32 Schemmer P, Friess H, Hinz U, et al: Stapler hepatectomy is a safe dissection technique: analysis of 300 patients. World J Surg 2006;30:419-430.

33 Bruns H, Kratschmer K, Hinz U, et al: Quality of life after curative liver resection: a single center analysis. World J Gastroenterol 2010;16:2388-2395.

34 Rahbari NN, Elbers $\mathrm{H}$, Koch M, et al: Clamp-crushing versus stapler hepatectomy for transection of the parenchyma in elective hepatic resection (CRUNSH)-a randomized controlled trial (NCT01049607). BMC Surg 2011;11:22 doi:10.1186/1471-2482-11-22.

35 Rahbari NN, Wente MN, Schemmer P, et al: Systematic review and meta-analysis of the effect of portal triad clamping on outcome after hepatic resection. Br J Surg 2008;95:424-432 . 
36 Fukuda S, Okuda K, Imamura M, et al: Surgical resection combined with chemotherapy for advanced hepatocellular carcinoma with tumor thrombus: report of 19 cases. Surgery 2002;131:300-310.

37 Yang T, Lin C, Zhai J, et al: Surgical resection for advanced hepatocellular carcinoma according to Barcelona Clinic Liver Cancer (BCLC) staging. J Cancer Res Clin Oncol 2012;138:1121-1129.

38 Ishizawa T, Hasegawa K, Aoki T, et al: Neither multiple tumors nor portal hypertension are surgical contraindications for hepatocellular carcinoma. Gastroenterology 2008;134:1908-1916.

$39 \mathrm{Ng} \mathrm{KK}$, Vauthey JN, Pawlik TM, et al: Is hepatic resection for large or multinodular hepatocellular carcinoma justified? Results from a multi-institutional database. Ann Surg Oncol 2005;12:364-373.

40 Jarnagin WR: Management of small hepatocellular carcinoma: a review of transplantation, resection, and ablation. Ann Surg Oncol 2010;17:1226-1233.

41 Nagasue N, Yukaya H, Ogawa Y, et al: Human liver regeneration after major hepatic resection. A study of normal liver and livers with chronic hepatitis and cirrhosis. Ann Surg 1987;206:30-39.

42 Pagano MA, Tibaldi E, Gringeri E, et al: Tyrosine phosphorylation and liver regeneration: A glance at intracellular transducers. IUBMB Life 2012;64:27-35.

43 Breitenstein S, Apestegui C, Petrowsky H, et al: "State of the art" in liver resection and living donor liver transplantation: a worldwide survey of 100 liver centers. World J Surg 2009;33:797-803.

44 Thakrar PD, Madoff DC: Preoperative portal vein embolization: an approach to improve the safety of major hepatic resection. Semin Roentgenol 2011;46:142-153.

45 Farges O, Belghiti J, Kianmanesh R, et al: Portal vein embolization before right hepatectomy: prospective clinical trial. Ann Surg 2003;237:208-217.

46 Chang WT, Kao WY, Chau GY, et al: Hepatic resection can provide long-term survival of patients with nonearly-stage hepatocellular carcinoma: Extending the Indication for resection? Surgery 2012;152:809820.

47 Hanazaki K, Kajikawa S, Shimozawa N, et al: Survival and recurrence after hepatic resection of 386 consecutive patients with hepatocellular carcinoma. J Am Coll Surg 2000;191:381-388.

48 Portolani N, Coniglio A, Ghidoni S, et al: Early and late recurrence after liver resection for hepatocellular carcinoma: prognostic and therapeutic implications. Ann Surg 2006;243:229-235.

49 Kudo M: Adjuvant therapy after curative treatment for hepatocellular carcinoma. Oncology 2011;81(Suppl 1):50-55.

50 Chan AC, Poon RT, Cheung TT, et al: Survival analysis of re-resection versus radiofrequency ablation for intrahepatic recurrence after hepatectomy for hepatocellular carcinoma. World J Surg 2012;36:151-156.

51 Del Gaudio M, Ercolani G, Ravaioli M, et al: Liver transplantation for recurrent hepatocellular carcinoma on cirrhosis after liver resection: University of Bologna experience. Am J Transplant 2008;8:1177-1185.

$52 \mathrm{Hu} \mathrm{Z}$, Zhou J, Xu X, et al: Salvage liver transplantation is a reasonable option for selected patients who have recurrent hepatocellular carcinoma after liver resection. PLoS ONE 2012;7:e36587.

53 Tranchart H, Di Giuro G, Lainas P, et al: Laparoscopic resection for hepatocellular carcinoma: a matchedpair comparative study. Surg Endosc 2010;24:1170-1176.

54 Ito $\mathrm{K}$, Ito $\mathrm{H}$, Are C, et al: Laparoscopic versus open liver resection: a matched-pair case control study. J Gastrointest Surg 2009;13:2276-2283.

55 Gagner M, Rogula T, Selzer D: Laparoscopic liver resection: benefits and controversies. Surg Clin North Am 2004;84:451-462.

56 Sarpel U, Hefti MM, Wisnievsky JP, et al: Outcome for patients treated with laparoscopic versus open resection of hepatocellular carcinoma: case-matched analysis. Ann Surg Oncol 2009;16:1572-1577.

57 Ker CG, Chen JS, Kuo KK, et al: Liver Surgery for Hepatocellular Carcinoma: Laparoscopic versus Open Approach. Int J Hepatol 2011;2011:596792.

$58 \mathrm{Li} \mathrm{N}$, Wu YR, Wu B, Lu MQ: Surgical and oncologic outcomes following laparoscopic versus open liver resection for hepatocellular carcinoma: A meta-analysis. Hepatol Res 2012;42:51-59.

59 Yokoyama I, Sheahan DG, Carr B, et al: Clinicopathologic factors affecting patient survival and tumor recurrence after orthotopic liver transplantation for hepatocellular carcinoma. Transplant Proc 1991;23:2194-2196.

60 Ringe B, Pichlmayr R, Wittekind C, et al: Surgical treatment of hepatocellular carcinoma: experience with liver resection and transplantation in 198 patients. World J Surg 1991;15:270-285.

61 Iwatsuki S, Starzl TE, Sheahan DG, et al: Hepatic resection versus transplantation for hepatocellular carcinoma. Ann Surg 1991;214:221-228, discussion 228-229.

62 Poon RT, Fan ST, Lo CM, et al: Difference in tumor invasiveness in cirrhotic patients with hepatocellular carcinoma fulfilling the Milan criteria treated by resection and transplantation: impact on long-term survival. Ann Surg 2007;245:51-58.

63 Mazzaferro V, Llovet JM, Miceli R, et al: Predicting survival after liver transplantation in patients with hepatocellular carcinoma beyond the Milan criteria: a retrospective, exploratory analysis. Lancet Oncol 2009;10:35-43.

64 Lee SG, Hwang S, Moon DB, et al: Expanded indication criteria of living donor liver transplantation for hepatocellular carcinoma at one large-volume center. Liver Transpl 2008;14:935-945.

65 Sauer P, Kraus TW, Schemmer P, et al: Liver transplantation for hepatocellular carcinoma: is there evidence for expanding the selection criteria? Transplantation 2005;80:S105-S108.

66 Hoffmann K, Hinz U, Hillebrand N, et al: Risk factors of survival after liver transplantation for HCC: a multivariate single-center analysis. Clin Transplant 2011;25:E541-E551.

67 de Lope CR, Tremosini S, Forner A, et al: Management of HCC. J Hepatol 2012;56(Suppl 1):S75-S87.

68 Raia S, Nery JR, Mies S: Liver transplantation from live donors. Lancet 1989;2:497. 
69 Strong RW, Lynch SV, Ong TH, et al: Successful liver transplantation from a living donor to her son. N Engl J Med 1990;322:1505-1507.

70 Hashikura Y, Makuuchi M, Kawasaki S, et al: Successful living-related partial liver transplantation to an adult patient. Lancet 1994;343:1233-1234.

71 Sugawara Y, Makuuchi M: Living donor liver transplantation: present status and recent advances. Br Med Bull 2005;75-76:15-28.

72 Mehrabi A, Schemmer P, Schmidt J, et al: Heidelberg's first experiences in establishing a living-donation liver transplantation programme. Nephrol Dial Transplant 2004;19(Suppl 4):iv1-iv5.

73 Sauer P, Schemmer P, Uhl W, Encke J: Living-donor liver transplantation: evaluation of donor and recipient. Nephrol Dial Transplant 2004;19(Suppl 4):iv11-iv15.

74 Sandhu L, Sandroussi C, Guba M, et al: Living donor liver transplantation versus deceased donor liver transplantation for hepatocellular carcinoma: comparable survival and recurrence. Liver Transpl 2012;18:315322.

75 Taketomi A, Shirabe K, Toshima T, et al: The long-term outcomes of patients with hepatocellular carcinoma after living donor liver transplantation: a comparison of right and left lobe grafts. Surg Today 2012;42:559564.

76 Saidi RF, Jabbour N, Li Y, et al: Is left lobe adult-to-adult living donor liver transplantation ready for widespread use? The US experience (1998-2010). HPB (Oxford) 2012;14:455-460.

77 Schemmer P, Mehrabi A, Friess H, et al: Living related liver transplantation: the ultimate technique to expand the donor pool? Transplantation 2005;80:S138-S141.

78 Llovet JM, Mas X, Aponte JJ, et al: Cost effectiveness of adjuvant therapy for hepatocellular carcinoma during the waiting list for liver transplantation. Gut 2002;50:123-128.

79 DuBay DA, Sandroussi C, Kachura JR, et al: Radiofrequency ablation of hepatocellular carcinoma as a bridge to liver transplantation. HPB (Oxford) 2011;13:24-32.

80 Bouchard-Fortier A, Lapointe R, Perreault P, et al: Transcatheter arterial chemoembolization of hepatocellular carcinoma as a bridge to liver transplantation: a retrospective study. Int J Hepatol 2011;2011:974514.

81 Yao FY, Kerlan RK Jr, Hirose R, et al: Excellent outcome following down-staging of hepatocellular carcinoma prior to liver transplantation: an intention-to-treat analysis. Hepatology 2008;48:819-827.

82 Chapman WC, Majella Doyle MB, Stuart JE, et al: Outcomes of neoadjuvant transarterial chemoembolization to downstage hepatocellular carcinoma before liver transplantation. Ann Surg 2008;248:617-625.

83 De Luna W, Sze DY, Ahmed A, et al: Transarterial chemoinfusion for hepatocellular carcinoma as downstaging therapy and a bridge toward liver transplantation. Am J Transplant 2009;9:1158-1168.

84 Heckman JT, Devera MB, Marsh JW, et al: Bridging locoregional therapy for hepatocellular carcinoma prior to liver transplantation. Ann Surg Oncol 2008;15:3169-3177.

85 Wiesner RH, Freeman RB, Mulligan DC: Liver transplantation for hepatocellular cancer: the impact of the MELD allocation policy. Gastroenterology 2004;127:S261-S267.

86 Ravaioli M, Grazi GL, Ballardini G, et al: Liver transplantation with the Meld system: a prospective study from a single European center. Am J Transplant 2006;6:1572-1577.

87 Dutkowski P, Oberkofler CE, Bechir M, et al: The model for end-stage liver disease allocation system for liver transplantation saves lives, but increases morbidity and cost: a prospective outcome analysis. Liver Transpl 2011;17:674-684.

88 Dutkowski P, Oberkofler CE, Slankamenac K, et al: Are there better guidelines for allocation in liver transplantation? A novel score targeting justice and utility in the model for end-stage liver disease era. Ann Surg 2011;254:745-753, discussion 753.

89 Lau WY, Leung TW, Yu SC, et al: Percutaneous local ablative therapy for hepatocellular carcinoma: a review and look into the future. Ann Surg 2003;237:171-179.

90 Lubienski A, Bitsch RG, Schemmer P, et al: Long-term results of interventional treatment of large unresectable hepatocellular carcinoma (HCC): significant survival benefit from combined transcatheter arterial chemoembolization (TACE) and percutaneous ethanol injection (PEI) compared to TACE monotherapy. Rofo 2004;176:1794-1802.

91 Zhang ZM, Guo JX, Zhang ZC, et al: Therapeutic options for intermediate-advanced hepatocellular carcinoma. World J Gastroenterol 2011;17:1685-1689.

92 Tsochatzis EA, Germani G, Burroughs AK: Transarterial chemoembolization, transarterial chemotherapy, and intra-arterial chemotherapy for hepatocellular carcinoma treatment. Semin Oncol 2010;37:89-93.

93 Llovet JM, Real MI, Montana X, et al: Arterial embolisation or chemoembolisation versus symptomatic treatment in patients with unresectable hepatocellular carcinoma: a randomised controlled trial. Lancet 2002;359:1734-1739.

94 Lo CM, Ngan H, Tso WK, et al: Randomized controlled trial of transarterial lipiodol chemoembolization for unresectable hepatocellular carcinoma. Hepatology 2002;35:1164-1171.

95 Doffoël M, Bonnetain F, Bouche 0, et al: Multicentre randomised phase III trial comparing Tamoxifen alone or with Transarterial Lipiodol Chemoembolisation for unresectable hepatocellular carcinoma in cirrhotic patients (Federation Francophone de Cancerologie Digestive 9402). Eur J Cancer 2008;44:528-538.

96 Oliveri RS, Wetterslev J, Gluud C: Transarterial (chemo)embolisation for unresectable hepatocellular carcinoma. Cochrane Database Syst Rev 2011;CD004787.

97 Bruix J, Llovet JM, Castells A, et al: Transarterial embolization versus symptomatic treatment in patients with advanced hepatocellular carcinoma: results of a randomized, controlled trial in a single institution. Hepatology 1998;27:1578-1583. 
98 Tygstrup N, Winkler K, Mellemgaard K, et al: Determination of the hepatic arterial blood flow and oxygen supply in man by clamping the hepatic artery during surgery. J Clin Invest 1962;41:447-454.

99 Wilhelm SM, Adnane L, Newell P, et al: Preclinical overview of sorafenib, a multikinase inhibitor that targets both Raf and VEGF and PDGF receptor tyrosine kinase signaling. Mol Cancer Ther 2008;7:31293140.

100 Cheng AL, Kang YK, Chen Z, et al: Efficacy and safety of sorafenib in patients in the Asia-Pacific region with advanced hepatocellular carcinoma: a phase III randomised, double-blind, placebo-controlled trial. Lancet Oncol 2009;10:25-34.

101 Bruix J, Raoul JL, Sherman M et al: Efficacy and Safety of Sorafenib in Patients with Advanced Hepatocellular Carcinoma: Subanalyses of a Phase III Trial. J Hepatol 2012.

102 Lai CL, Wu PC, Chan GC, et al: Doxorubicin versus no antitumor therapy in inoperable hepatocellular carcinoma. A prospective randomized trial. Cancer 1988;62:479-483.

103 Hoffmann K, Franz C, Xiao Z, et al: Sorafenib modulates the gene expression of multi-drug resistance mediating ATP-binding cassette proteins in experimental hepatocellular carcinoma. Anticancer Res 2010;30:4503-4508.

104 Kudo M, Imanaka K, Chida N, et al: Phase III study of sorafenib after transarterial chemoembolisation in Japanese and Korean patients with unresectable hepatocellular carcinoma. Eur J Cancer 2011;47:21172127.

105 Sansonno D, Lauletta G, Russi S, et al: Transarterial chemoembolization plus sorafenib: a sequential therapeutic scheme for HCV-related intermediate-stage hepatocellular carcinoma: a randomized clinical trial. Oncologist 2012;17:359-366.

$106 \mathrm{Qu}$ XD, Chen C, Wang J, et al: The efficacy of TACE combined sorafenib in advanced stages hepatocellullar carcinoma. BMC Cancer 2012;12:263 doi:10.1186/1471-2407-12-263.

107 Hoffmann K, Glimm H, Radeleff B, et al: Prospective, randomized, double-blind, multi-center, Phase III clinical study on transarterial chemoembolization (TACE) combined with Sorafenib versus TACE plus placebo in patients with hepatocellular cancer before liver transplantation - HeiLivCa [ISRCTN24081794]. BMC Cancer 2008;8:349 doi:10.1186/1471-2407-8-349.

108 Fuchs CS, Clark JW, Ryan DP, et al: A phase II trial of gemcitabine in patients with advanced hepatocellular carcinoma. Cancer 2002;94:3186-3191.

109 Yeo W, Mok TS, Zee B, et al: A randomized phase III study of doxorubicin versus cisplatin/interferon alpha-2b/doxorubicin/fluorouracil (PIAF) combination chemotherapy for unresectable hepatocellular carcinoma. J Natl Cancer Inst 2005;97:1532-1538.

110 Thomas MB, O’Beirne JP, Furuse J, et al: Systemic therapy for hepatocellular carcinoma: cytotoxic chemotherapy, targeted therapy and immunotherapy. Ann Surg Oncol 2008;15:1008-1014.

111 Sciarrino E, Simonetti RG, Le Moli S, et al: Adriamycin treatment for hepatocellular carcinoma. Experience with 109 patients. Cancer 1985;56:2751-2755.

112 Yang TS, Lin YC, Chen JS, et al: Phase II study of gemcitabine in patients with advanced hepatocellular carcinoma. Cancer 2000;89:750-756.

113 Sanyal AJ, Yoon SK, Lencioni R: The etiology of hepatocellular carcinoma and consequences for treatment. Oncologist 2010;15(Suppl 4):14-22.

114 Kim BK, Kim SU, Park JY, et al: Applicability of BCLC stage for prognostic stratification in comparison with other staging systems: single centre experience from long-term clinical outcomes of 1717 treatment-naive patients with hepatocellular carcinoma. Liver Int 2012;32:1120-1127.

115 Sirivatanauksorn Y, Tovikkai C: Comparison of staging systems of hepatocellular carcinoma. HPB Surg 2011;2011:818217.

116 Chan SL, Mo FK, Johnson PJ, et al: Prospective validation of the Chinese University Prognostic Index and comparison with other staging systems for hepatocellular carcinoma in an Asian population. J Gastroenterol Hepatol 2011;26:340-347.

117 Kawaoka T, Aikata H, Takaki S, et al: Transcatheter chemoembolization for unresectable hepatocellular carcinoma and comparison of five staging systems. Hepatol Res 2010;40:1082-1091.

118 Hsu CY, Hsia CY, Huang YH, et al: Selecting an optimal staging system for hepatocellular carcinoma: comparison of 5 currently used prognostic models. Cancer 2010;116:3006-3014.

119 Huitzil-Melendez FD, Capanu M, O’Reilly EM, et al: Advanced hepatocellular carcinoma: which staging systems best predict prognosis? J Clin Oncol 2010;28:2889-2895.

120 Zhang XF, Qi X, Meng B, et al: Prognosis evaluation in alpha-fetoprotein negative hepatocellular carcinoma after hepatectomy: comparison of five staging systems. Eur J Surg Oncol 2010;36:718-724.

121 Chung H, Kudo M, Takahashi S, et al: Comparison of three current staging systems for hepatocellular carcinoma: Japan integrated staging score, new Barcelona Clinic Liver Cancer staging classification, and Tokyo score. J Gastroenterol Hepatol 2008;23:445-452.

122 Lu W, Dong J, Huang Z, et al: Comparison of four current staging systems for Chinese patients with hepatocellular carcinoma undergoing curative resection: Okuda, CLIP, TNM and CUPI. J Gastroenterol Hepatol 2008;23:1874-1878.

123 Cammà C, Di Marco V, Cabibbo G, et al: Survival of patients with hepatocellular carcinoma in cirrhosis: a comparison of BCLC, CLIP and GRETCH staging systems. Aliment Pharmacol Ther 2008;28:62-75.

124 Collette S, Bonnetain F, Paoletti X, et al: Prognosis of advanced hepatocellular carcinoma: comparison of three staging systems in two French clinical trials. Ann Oncol 2008;19:1117-1126.

125 Cho YK, Chung JW, Kim JK, et al: Comparison of 7 staging systems for patients with hepatocellular carcinoma undergoing transarterial chemoembolization. Cancer 2008;112:352-361. 
126 Guglielmi A, Ruzzenente A, Pachera S, et al: Comparison of seven staging systems in cirrhotic patients with hepatocellular carcinoma in a cohort of patients who underwent radiofrequency ablation with complete response. Am J Gastroenterol 2008;103:597-604.

127 Kondo K, Chijiiwa K, Nagano M, et al: Comparison of seven prognostic staging systems in patients who undergo hepatectomy for hepatocellular carcinoma. Hepatogastroenterology 2007;54:1534-1538.

128 Chen TW, Chu CM, Yu JC, et al: Comparison of clinical staging systems in predicting survival of hepatocellular carcinoma patients receiving major or minor hepatectomy. Eur J Surg Oncol 2007;33:480-487.

129 Feng K, Yan J, Li X, et al: A randomized controlled trial of radiofrequency ablation and surgical resection in the treatment of small hepatocellular carcinoma. J Hepatol 2012;57:794-802.

130 Ruzzenente A, Guglielmi A, Sandri M, et al: Surgical resection versus local ablation for HCC on cirrhosis: results from a propensity case-matched study. J Gastrointest Surg 2012;16:301-311, discussion 311.

131 Huang J, Hernandez-Alejandro R, Croome KP, et al: Radiofrequency ablation versus surgical resection for hepatocellular carcinoma in Childs A cirrhotics-a retrospective study of 1,061 cases. J Gastrointest Surg 2011;15:311-320.

132 Hung HH, Chiou YY, Hsia CY, et al: Survival rates are comparable after radiofrequency ablation or surgery in patients with small hepatocellular carcinomas. Clin Gastroenterol Hepatol 2011;9:79-86.

133 Nishikawa $\mathrm{H}$, Inuzuka T, Takeda $\mathrm{H}$, et al: Comparison of percutaneous radiofrequency thermal ablation and surgical resection for small hepatocellular carcinoma. BMC Gastroenterol 2011;11:143 doi:10.1186/1471230X-11-143.

134 Huang J, Yan L, Cheng Z, et al: A randomized trial comparing radiofrequency ablation and surgical resection for HCC conforming to the Milan criteria. Ann Surg 2010;252:903-912.

135 Trinchet JC, Rached AA, and Beaugrand M, et al: A comparison of lipiodol chemoembolization and conservative treatment for unresectable hepatocellular carcinoma. Groupe d'Etude et de Traitement du Carcinome Hepatocellulaire. N Engl J Med 1995;332:1256-1261.

136 Zhou Y, Zhao Y, Li B, et al: Meta-analysis of radiofrequency ablation versus hepatic resection for small hepatocellular carcinoma. BMC Gastroenterol 2010;10:78 doi:10.1186/1471-230X-10-78.

137 Germani G, Pleguezuelo M, Gurusamy K, et al: Clinical outcomes of radiofrequency ablation, percutaneous alcohol and acetic acid injection for hepatocelullar carcinoma: a meta-analysis. J Hepatol 2010;52:380-388.

138 Bouza C, Lopez-Cuadrado T, Alcazar R, et al: Meta-analysis of percutaneous radiofrequency ablation versus ethanol injection in hepatocellular carcinoma. BMC Gastroenterol 2009;9:31 doi:10.1186/1471-230X-9-31.

139 Schoppmeyer K, Weis S, Mossner J, et al: Percutaneous ethanol injection or percutaneous acetic acid injection for early hepatocellular carcinoma. Cochrane Database Syst Rev 2009;CD006745. 